\title{
Reacción leucoeritroblástica. Presentación poco frecuente de leucemia aguda en niños
}

\section{Leukoerythroblastic reaction. Unusual presentation of acute leukemia in children}

\author{
Díaz-Silva, Víctor ${ }^{1 \mathrm{a}, \mathrm{d}}$; Yovera-Puican, Angela ${ }^{1, \mathrm{~b}}$; Yuptón-Chávez, Verónica ${ }^{1, \mathrm{c}}$
}

La reacción leucoeritroblástica es un hallazgo del frotis de sangre periférica caracterizada por la presencia de células precursoras mieloides (meta-mielocitos, mielocitos y pro-mielocitos) y de hematíes nucleados (eritroblastos). En algunas ocasiones pueden asociarse con alteraciones morfológicas en los eritrocitos como la presencia de dacriocitos ${ }^{(1)}$.

El síndrome leucoeritroblástico puede aparecer en diferentes enfermedades neoplásicas ${ }^{(1,2)}$, infecciosas (Parvovirus B19 ${ }^{(3)}$, malaria grave ${ }^{(4)}$ ), mielofibrosis, anemias hemolíticas o hemorragia grave. Es muy poco frecuente en la población pediátrica, limitado de forma casi exclusiva a procesos infecciosos ${ }^{(5)}$.

Se presentan los casos de dos niños en que el estudio inicial del frotis se observa una reacción leucoeritroblástica y, posteriormente, entre siete y 10 días, se evidencia blastos en el frotis. El primer caso es el de un niño de ocho años con bicitopenia que 10 días más tarde fue diagnosticado de una leucemia linfoblástica aguda (Figura 1). El segundo caso es el de una niña de cinco años con bicitopenia en la que en los 7 días posteriores a su ingreso se detectó la presencia de blastos monocitoides diagnosticándosele leucemia mieloide aguda (Figura 2).
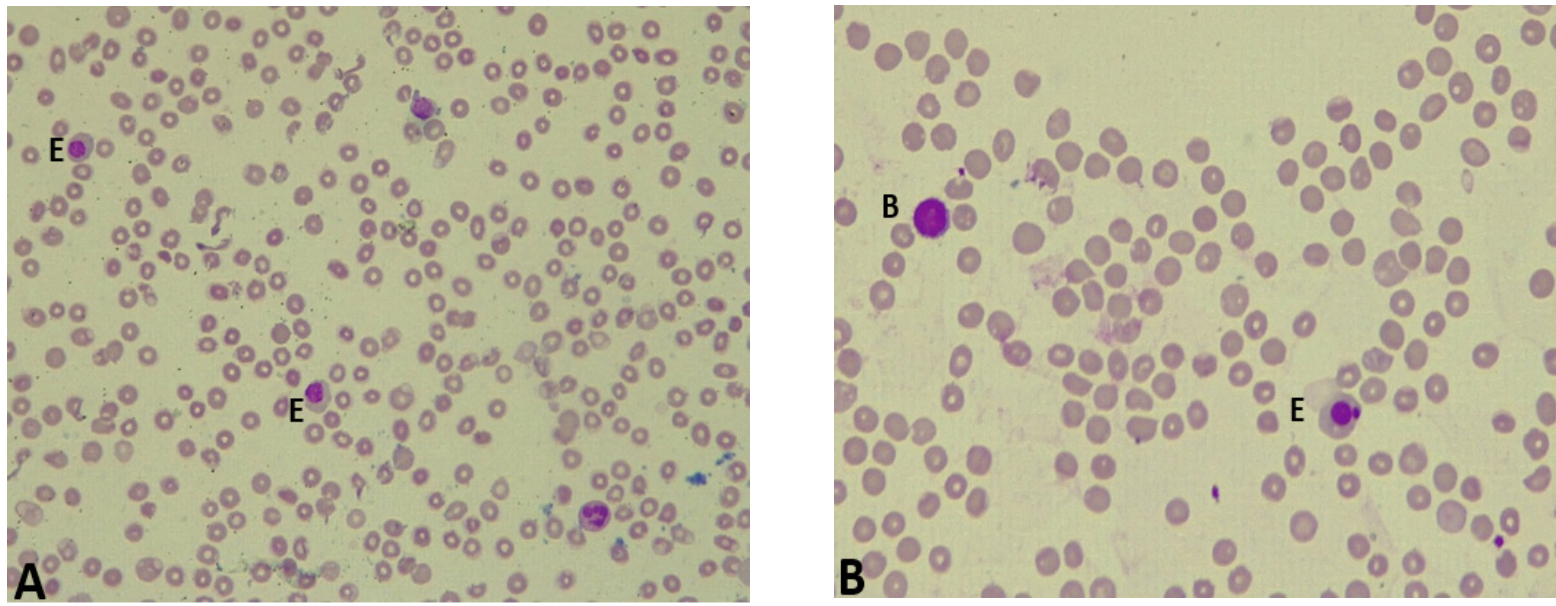

Figura 1. Frotis de hemograma del primer caso. A: Lectura inicial donde se observa eritroblastos (E). Tin ción Wright. 100x. B: Lectura a la semana del ingreso donde se observa blastos de aspecto linfoide (B) y eritroblastos (E). Tinción Wright. 400x.

\footnotetext{
${ }^{1}$ Hospital Regional de Lambayeque, Chiclayo, Perú.

${ }^{a}$ Hematólogo clínico

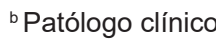

${ }^{\mathrm{c}}$ Analista clínico

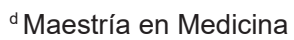



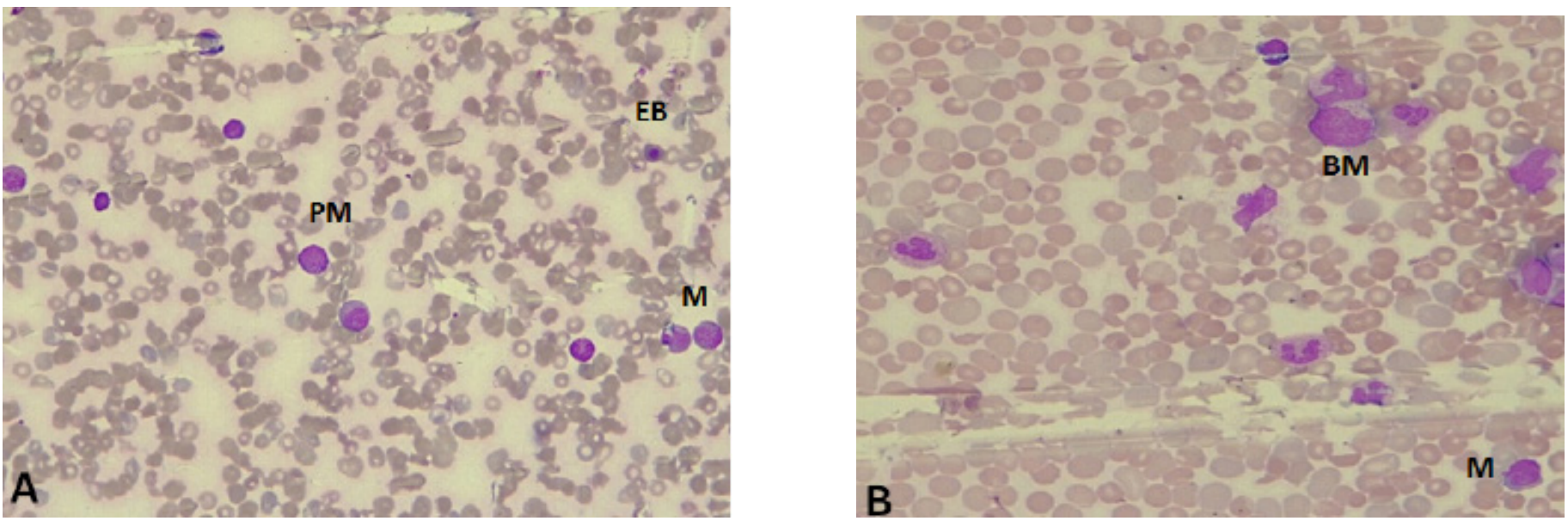

Figura 2. Frotis de hemograma del segundo caso $A$ : Lectura inicial donde se observa monocitos de apariencia displásica (M), precursores mieloides (PM) y eritroblastos (EB). Tinción Wright - 100x. B: Lectura a los 10 días de evolución donde se visualiza blastos de aspecto monocitoide (BM) y monocitos displásicos (M). Tinción Wright - 400x.

Conflictos de interés: Los autores declaran que no existe conflictos de intereses.

Fuentes de financiamiento: Autofinanciado

\section{REFERENCIAS BIBLIOGRÁFICAS}

1. Byard PW, Bormanis J, Jones TG. Leukoerythroblastosis in breast carcinoma. Lancet 1987; 2(8561):744. https://doi:10.1016/s0140-6736(87)91105-6

2. Tabares-Calvache E, Tabares-Calvache AD, Faulhaber GAM. Systematic review about etiologic association to the leukoerythroblastic reaction. Int $J$ Lab Hematol. 2020; 42:495-500. Disponible en: https://doi:10.1111/ijlh.13238

3. Mathew A, Abuhammour W, Fathalla B, Otour B. Parvovirus B19 Infection Mimicking Juvenile Myelomonocytic Leukemia in an Immunocompetent Child. Cureus, 2020; 12(6), e8854. Disponible en: https://doi.org/10.7759/cureus.8854

4. Varo R, Sitoe A, Cossa A, Ordi J, Rozman M, Bassat Q. Leukoerythroblastosis in a Young Child with Severe Malaria and Superimposed Gram Negative Infection. Journal of Tropical Pediatrics. 2018; 64(6): 553-6. Disponible en: https://doi.org/10.1093/tropej/fmx101

5. Costa A, Volosky R. Reacciones Leucemoides e Hiperleucocitosis en Clínica Infantil. Rev. chil. pediatr. [Internet]. 1955 [citado 2020 Nov 26]; 26 (4): 151-9. Disponible en: https://scielo.conicyt.cl/scielo.php?script=sci_arttext\&pid=S0370-41061955000400002\&lng=es. http://dx.doi.org/10.4067/S0370-

1061955000400002 